\title{
Family experiences with palliative care for children at home: a systematic literature review
}

Anette Winger ${ }^{1 *} \mathbb{D}$, Lisbeth Gravdal Kvarme¹, Borghild Løyland', Camilla Kristiansen², Sølvi Helseth and Ingrid H. Ravn'

\begin{abstract}
Background: The main goal of pediatric palliative care (PPC) is to improve or maintain the best possible quality of life (QoL) for the child and their family. PPC can be provided in community health centres, within the specialist health care service and/or in the child's home. Home is often the preferred place for families, and recommendations state that, whenever possible, the family home should be the centre of care for the child. The aim of this study is to systematically review the experiences and needs of families with children receiving palliative care at home.
\end{abstract}

Methods: We conducted a systematic review and searched the peer-reviewed databases CINAHL, Embase, Psyclnfo and MEDLINE for articles published between January 2000 and October 2019. We included 23 studies emphasising the experience of family members when their child (0-18 years) received palliative care at home. We used a thematic analysis to identify relevant themes in the literature, and synthesised the findings from the different studies.

Results: The review represents the experiences of the families of almost 300 children with life-limiting $(L L)$ and lifethreatening (LT) conditions receiving palliative care at home. In general, the children's mothers are interviewed, and seldom the sick children themselves or their siblings. Most families preferred staying at home since it made it easier to maintain a normal family life, was less stressful for the sick child, and meant that siblings could still attend school and be with friends. Families experienced a range of challenges due to the coordination of care, including a lack of support and adequately skilled staff with appropriate experience. Respite care was needed in order to cope with everyday life. Some studies were not specific concerning the place of care, and some relevant papers may have been omitted.

Conclusions: Families receiving PPC need organised, individualised support from a skilled PPC team. Respite care is necessary in order to manage a demanding home-care situation and parents need support for siblings. Privacy to be a family is a need, and many families need financial support. Future studies should focus on PPC at home in the perspectives of sick children and their siblings.

Keywords: Pediatric palliative care, PPC, Child, Home care, Family, Life threatening condition, Life limiting condition, Sibling, Parents, Family centred care

\footnotetext{
* Correspondence: anwin@oslomet.no

'Oslo Metropolitan University (OsloMet), P.O. Box 4 St. Olavs plass, NO-0130

Oslo, Norway

Full list of author information is available at the end of the article
}

(c) The Author(s). 2020 Open Access This article is licensed under a Creative Commons Attribution 4.0 International License, which permits use, sharing, adaptation, distribution and reproduction in any medium or format, as long as you give appropriate credit to the original author(s) and the source, provide a link to the Creative Commons licence, and indicate if changes were made. The images or other third party material in this article are included in the article's Creative Commons licence, unless indicated otherwise in a credit line to the material. If material is not included in the article's Creative Commons licence and your intended use is not permitted by statutory regulation or exceeds the permitted use, you will need to obtain permission directly from the copyright holder. To view a copy of this licence, visit http://creativecommons.org/licenses/by/4.0/ The Creative Commons Public Domain Dedication waiver (http://creativecommons.org/publicdomain/zero/1.0/) applies to the data made available in this article, unless otherwise stated in a credit line to the data. 


\section{Background}

The number of children in need of palliative care is not known, but could range from 120 per 10,000 children in Zimbabwe to approximately 20 per 10,000 in the United Kingdom [1]. Pediatric palliative care (PPC) is provided to children with a wide range of life-threatening (LT) or life-limiting (LL) conditions such as congenital anomalies, cancer and neurological conditions [2]. A higher proportion of children than adults receiving palliative care have non-cancer diagnoses. Due to demographic and technological changes, the concept of PPC has evolved to address the needs of patient populations that may not be characterised as dying, but to whom relief of suffering and optimisation of quality of life (QoL) are important [3]. The main goal of PPC is to improve or maintain the best possible QoL for the child and their family. PPC can be provided in community health centres, within the specialist health care service and/or in the child's home, which includes taking care of the children and families' physical, psychological, social and spiritual needs, and following up the child's family after death [4]. Children often receive more aggressive treatment than adults and are therefore more often in a hospital when they receive palliative care [5]. Hospitals provide high-quality palliative care for children with lifethreatening illnesses [6] and, so far, advanced care for children at home is seldom offered to those with LT and LL diseases [7]. Home is, however, often the preferred place for many families when their child is in need of PPC and end-of-life care [8,9], and some evidence supports that children and their families would benefit from palliative care at home [10]. The American Academy of Pediatrics supports that palliative care should be accessible in any setting, including home, hospital and school [11]. The services available to children and the families vary; some countries have a well-established program for children's palliative care with both pediatric hospice facility, children's hospital and community based palliative care $[9,12]$. When choosing between home, hospital and hospice, families tends to choose end of life care and death at home $[9,12]$, even though the study by Siden et al. (2008) show that the choice of families for end-oflife care is almost equally divided amongst all three options. The study reports on actual location of death and it is unclear if location are based on actual choices [12]. However, many children and families are not given a choice of location for care at the end of life, and the availability of advanced home care is limited [7, 13]. Also, families experience lack of knowledge and insufficient organisation of health care outside hospitals, which is not customised to meet their needs [14]. One systematic review conclude that experience of death at home is complex and underpin the need for rigorous research with data from both parents, children and siblings [15].
Evidence has shown that there is a need for tailored support with more flexibility in the care provided, the location of care and access to psychosocial support, respite care and sibling support [16]. Recommendations state that, whenever possible, the family home should be the centre of care for the child [17]. Since the evidence also shows that many families want their severely ill child to be cared for at home, we found it expedient to provide an overview of children receiving PPC at home and their family's experience with home care. Since home is the preferred place for many families when their child is in need of PPC and end-of-life care, the aim of this study is to systematically review the experiences and needs of the families when children receive palliative care at home.

\section{Methods \\ Eligibility criteria}

The target population was children in palliative care from birth to the age of 19 (0-18), and their families, who live at home. Family members might for example include grandparents or other relatives. There were no restrictions as to diagnosis, but the condition had to be defined as LT and LL in line with WHO's definition of palliative care for children [4]. Inclusion criteria were articles from 2000 to 2019, focusing on children (0-18 years) and their families receiving palliative care at home (see Table 1). Some articles included young persons up to the age of 21 , while the main emphasis was on persons under the age of 18. Exclusion criteria were review articles and conference abstracts, and cases where the child mainly received palliative care in a hospice or hospital.

\section{Table 1 Criteria for inclusion and exclusion}

\begin{tabular}{|c|c|}
\hline $\begin{array}{l}\text { Criteria for } \\
\text { inclusion }\end{array}$ & $\begin{array}{l}\text { - Children (0-18) receiving palliative care at home } \\
\text { - Papers in English or a Scandinavian language } \\
\text { - Papers from January } 2000 \text { to January } 2018 \\
\text { - Families' and family members' experiences of } \\
\text { palliative home care (qualitative or quantitative, } \\
\text { interviews or questionnaires) } \\
\text { - Children with a life-limiting or life-shortening } \\
\text { condition } \\
\text { - Qualitative, quantitative and mixed methods design }\end{array}$ \\
\hline $\begin{array}{l}\text { Criteria for } \\
\text { exclusion }\end{array}$ & $\begin{array}{l}\text { - Palliative care in people }>18 \\
\text { - Studies including both adult and children palliative } \\
\text { care } \\
\text { - Papers concerning research on symptoms and } \\
\text { symptom management collected from medical } \\
\text { records or from health care professionals } \\
\text { - Nursing homes } \\
\text { - Review papers } \\
\text { - Book chapters } \\
\text { - Conference abstracts } \\
\text { - Citations without an abstract } \\
\text { - Case reports } \\
\text { - Papers evaluating a palliative care programme or } \\
\text { therapy, but not based on the experience of families } \\
\text { of children with LL or LT conditions }\end{array}$ \\
\hline
\end{tabular}




\section{Search strategy}

A systematic literature search was started in August 2016 and was conducted in CINAHL, Embase, PsycInfo and MEDLINE (see Table 2). A further updated search was performed in October 2019. The identified articles were transferred to an EndNote library for screening and removal of duplicates. Articles meeting the inclusion criteria were included and analysed. The review also included families staying occasionally at a hospital or hospice for short periods, provided that palliative care was mainly given at home. We therefore also conducted a separate search that including the term 'hospice'. Updated searches were performed between the initial search and October 2019. In total, 23 papers are included in this review.

\section{Data collection}

Two authors (AW and IHR) independently reviewed titles and abstracts and identified 2940 citations. We made a separate search for the term 'hospice', and 52 additional papers were detected and are included in the total number of citations. Duplicates were removed (592) and the titles and content of 2348 abstracts were read by the researchers in pairs (LGK \& SH, BL \& CK, IHR \& AW). Consensus was obtained when excluding 2178 citations. The remaining 170 articles underwent full-text review to determine whether they met the inclusion criteria, and 147 papers were excluded. Discrepancies among reviewers were discussed in the group until consensus was reached. The remaining 23 papers were included and analysed (LGK, IHR and AW). The search strategy is outlined in Fig. 1.

\section{Data analysis}

This systematic review uses the structure of thematic analysis, identifying themes in the literature and synthesising the findings from the different studies [18]. Dixon-Woods et al. (2005) describe different methods when synthesising evidence, finding that thematic analysis involves the identification of prominent or recurrent themes in the literature, and summarising the findings of different studies under thematic headings. The authors used the retrieved articles to generate and set the themes and sub-themes within this review. Bearing the research question in mind, themes were recognised by identifying issues relevant to family members when their child received palliative care at home. In the process of summarising the findings, the extracted evidence was repeatedly reviewed by three researchers (AW, LGK and IHR). We organized the findings under the following categories: Homebased palliative care - the experiences of parents, children and siblings and, challenges and unmet needs at home. (see Table 3).

\section{Data extraction}

The first author (AW) extracted information from the included studies and two authors checked the results (LK and IHR). The following information was extracted from all the included studies: References and country for data collection, aim of the study, the children's diagnoses, study design and analysis, participants, results, and scores in the Critical Appraisal Skills Programme (CASP scores) [19].

\section{Quality assessment}

To apprise the methodological quality, the articles were assessed using the CASP [19]. The assessment identified 20 studies of high quality ( $>8$ out of 10 scores), and 3 of moderate quality (4-6 out of 10). None of the studies were categorised as being of poor quality. All studies were independently assessed by two reviewers in pairs, half by IHR and LGK, and all by AW.

Table 2 Search strategy

\begin{tabular}{ll}
\hline Ovid MEDLINE(R) & AND \\
\hline Searches & $\begin{array}{l}\text { adolescent/ or child/ or child, preschool/ or infant/ or infant, } \\
\text { newborn/ or infant, low birth weight/ or infant, small for gestational } \\
\text { age/ or infant, very low birth weight/ or infant, extremely low birth } \\
\text { weight/ or infant, premature/ or infant, extremely premature/ }\end{array}$ \\
$\begin{array}{l}\text { Advance Care Planning/ } \\
\text { Terminally III/ (palliative or palliation } \\
\text { or terminal care or end of life } \\
\text { care).tw. }\end{array}$ & $\begin{array}{l}\text { Pediatrics/ family/ or family relations/ or parent-child relations/ or par- } \\
\text { enting/ or sibling relations/ or grandparents/ or single-parent family/ } \\
\text { home care services/ or home care } \\
\text { services, hospital-based/ or home } \\
\text { nursing/ } \\
\text { (home or homecare or familiar } \\
\text { surrounding* or familiar } \\
\text { environment).tw. }\end{array}$ \\
$\begin{array}{l}\text { parents/ or fathers/ or mothers/ or single parent/ or siblings/ } \\
\text { Caregivers/ (child* or paediatric or pediatric or neonat* or newborn or } \\
\text { infant* or adolescent* or youth or juvenile or family or families or } \\
\text { parent* or sibling* or mother* or father* or brother* or sister* or } \\
\text { grandparent* or relative* or next of kin or care giver* or caregiver* or } \\
\text { uncle* or aunt*).tw. }\end{array}$
\end{tabular}

AND

limit 18 to (yr = "1982-Current" and (Danish or English or Norwegian or Swedish)) 


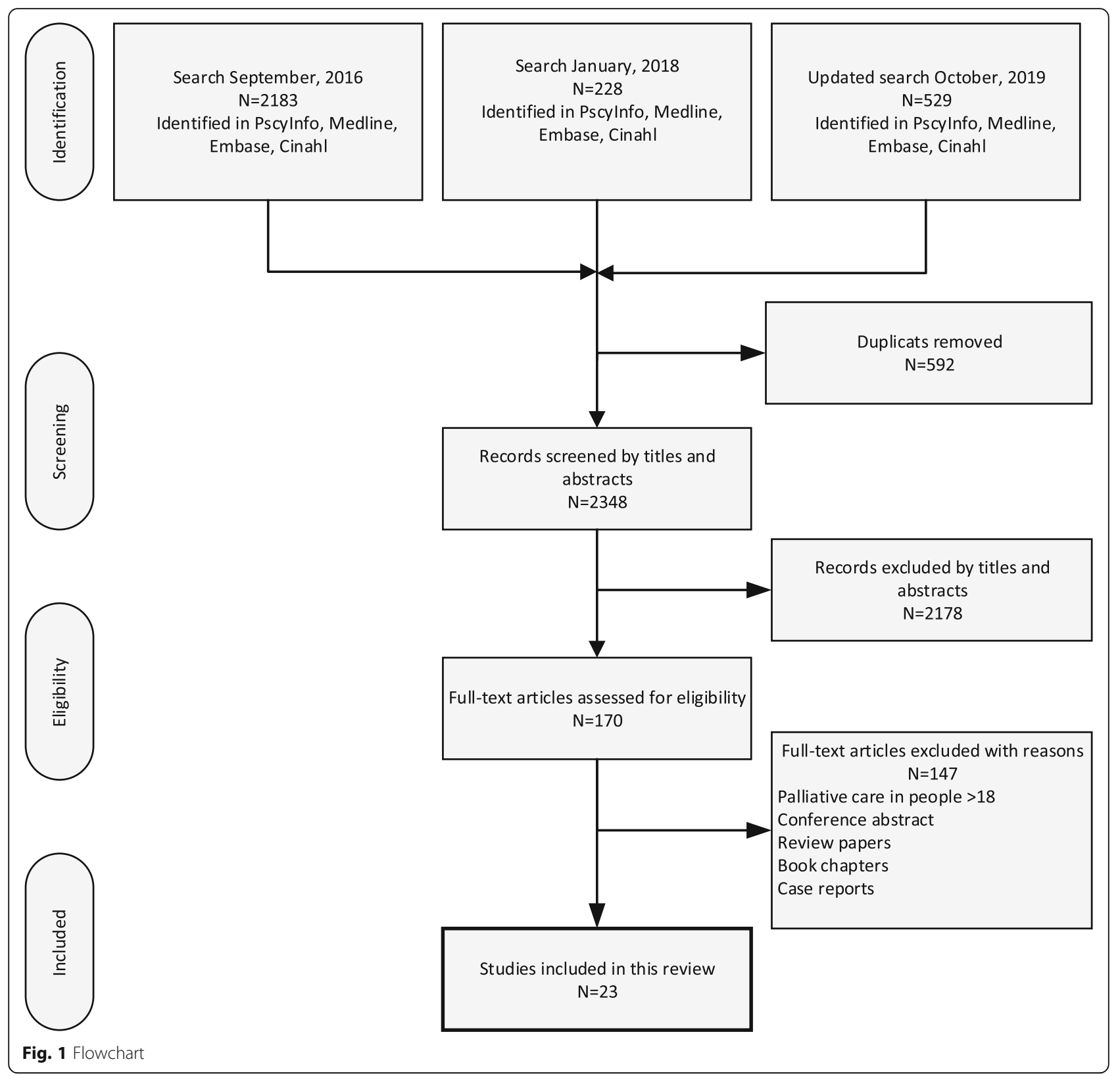

Table $\mathbf{3}$ analysis of the family experiences when children receive palliative care at home

\begin{tabular}{|c|c|c|c|c|c|c|}
\hline \multirow{2}{*}{$\begin{array}{l}\text { Categories } \\
\text { Themes }\end{array}$} & \multicolumn{3}{|c|}{$\begin{array}{l}\text { Text concerning home-based palliative care - the expe- } \\
\text { riences of parents, children and siblings }\end{array}$} & \multicolumn{3}{|c|}{ Text concerning challenges and unmet needs at home } \\
\hline & $\begin{array}{l}\text { Parents' } \\
\text { experiences }\end{array}$ & $\begin{array}{l}\text { Children's } \\
\text { experiences }\end{array}$ & $\begin{array}{l}\text { Siblings' } \\
\text { experiences }\end{array}$ & Challenges & Needs & $\begin{array}{l}\text { Importance of } \\
\text { support and } \\
\text { respite care }\end{array}$ \\
\hline $\begin{array}{l}\text { Sub- } \\
\text { themes }\end{array}$ & $\begin{array}{l}\text { Place of care. } \\
\text { Positive } \\
\text { consequences of } \\
\text { home care. }\end{array}$ & $\begin{array}{l}\text { Wanted to stay } \\
\text { at home. } \\
\text { Physician } \\
\text { showed interest } \\
\text { in their person. } \\
\text { Need for } \\
\text { information } \\
\text { without parents } \\
\text { presence. }\end{array}$ & $\begin{array}{l}\text { Difficult emotions. } \\
\text { Home care made a } \\
\text { normal life possible. }\end{array}$ & $\begin{array}{l}\text { Importance of } \\
\text { support. } \\
\text { Lack of competence } \\
\text { and organizations. } \\
\text { Lack of privacy. } \\
\text { Lack of trust but also } \\
\text { satisfaction with } \\
\text { health care providers. } \\
\text { Work and economy }\end{array}$ & $\begin{array}{l}\text { Communication with health } \\
\text { care professionals. Heavily } \\
\text { workload. Fighting for } \\
\text { resources. }\end{array}$ & $\begin{array}{l}\text { Respite care } \\
\text { impotent for } \\
\text { parents to } \\
\text { cope. } \\
\text { Pediatric } \\
\text { palliative care } \\
\text { teams. }\end{array}$ \\
\hline
\end{tabular}




\section{Results}

\section{Studies and study characteristics}

The articles included in this review represent different designs, (see Table 4) and included the experiences of 115 families of 281 children ( $0-21$ years) with LL and LT conditions. Three studies included children above the age of 18 (0-21 years), and three studies did not state the age of the sick children. Seven studies were conducted in North America and Canada, six in the United Kingdom and three in Germany. The Netherlands was represented with four studies, Switzerland with two studies and Sweden and Indonesia had one study each. Twenty-two studies were qualitative studies. There were approximately 300 interviews in the included studies, more mothers (194) than fathers (78) were interviewed, and few of the children themselves. It is not possible to identify the exact number of children who gave responses or participated in the studies due to lack of information. One study used surveys including both open and closed-ended questions [20]. The studies used medical records or questionnaires to provide information about socio-demographic data and the children's diagnoses.

\section{Home-based palliative care - the experiences of parents, children and siblings}

In the included studies, palliative care was mainly provided at home, but palliative care or respite care was also provided in hospitals or at children's hospices. The studies, mostly from western countries, problematize the place of care and/or place of death, and a majority of families preferred home as the place of care or terminal care (place of death) [21-25]. They focused mainly on the parents' experiences and needs, or the needs of the child as narrated by their parents. Only three articles reported that the children were interviewed with a focus on the child's own experiences [21, 26, 27]. Kars et al. (2015) asked parents how they gained insight into their child's perspective, how they acknowledged the 'voice of the child', and took their child's perspective into account [28]. They concluded that although the parents were intensely involved in their child's life, it was difficult to acknowledge the child's perspective due to the parents' own struggle to cope with loss [28]. Families can be seen in a broader sense and might include grandparents, other relatives and even friends. As such, other significant persons like grandparents were interviewed in some of the studies. In one study, the parents emphasised that staying at home made it easier for the grandparents to meet their grandchildren [21].

\section{Parents' experiences}

For some parents, the preferred location of death shifted between home and hospital, but it was most important for the families to have a choice [27]. 'Our hopes are that his passing. .. the hospital will let us bring him home so he can pass [die] where he is comfortable. He will have that sense of love and belonging, whereas in a situation filled with pain and he has to be hooked up to a bunch of different things at the hospital and we can't take him home, he wouldn't be comfortable. I think he deserves to be comfortable when he does pass.' [27]. A study from the Netherlands [28] claims that children are increasingly cared for at home, assuming that the needs of dying children can best be taken care of at home [28]. Families appreciate the normality of home care [23], and a range of positive consequences were highlighted, such as fulfilling the child's and the parents' desire to stay at home and take care of their child in a less stressful environment. Further, the involvement of extended family and friends contributed to keeping the family together, strengthening family life, maintaining the daily activities of siblings, and involving grandparents in care and health promotion [21]. However, the alliance between the family, home care and hospital care was a condition for the success of home-based care. Other positive consequences from staying at home were found to be a closer relationship between parents and nurses than in a depersonalised hospital system [25] more emotional support, and care and practical support from family and friends, which enabled parents to spend more time with their child [20, 29]. Several families had support from palliative care teams and findings suggested that competent palliative home care teams might increase the wellbeing and quality of life of the whole family [21, 30]. Although the responsibility for their child entailed both concerns and fears, many parents considered home to be the place of choice for respite care [22, 23]. Being at home, with the support of health care providers, contributed to the parents' coping, despite the complexity and burden of the circumstances surrounding care of their child $[21,31]$.

\section{Children's experiences}

The sick child often preferred to stay at home [21], whereby the child saved both time and energy that could be used for social interactions with friends: 'It was hard to go to the hospital again and again and I told them that I can't come because I get tired and don't have the strength to do anything.' (Sick child 9, Informant in Castor et al., 2018) [21].. Another important issue for children was physicians who spent more time getting to know the child, and showed interest in both their personal and social concerns [26]. Parents and children sometimes disagreed on the physician's level of involvement in their child's care. Being honest about the medical situation and giving the child different choices, and the opportunity to talk to the doctor without the 
Table 4 Study characteristics

\begin{tabular}{|c|c|c|}
\hline $\begin{array}{l}\text { Study and } \\
\text { language/country }\end{array}$ & Aim of the study & Diagnosis \\
\hline $\begin{array}{l}\text { Champagne M. and } \\
\text { Ongeau S. (2012): } \\
\text { Effects of respite care } \\
\text { services in a children's } \\
\text { hospice: the parents' } \\
\text { point of view } \\
\text { English/Canada }\end{array}$ & $\begin{array}{l}\text { To describe parents' } \\
\text { perspective and } \\
\text { ability to care. } \\
\text { To analyze, from the } \\
\text { parents' point of view, } \\
\text { the effects of respite } \\
\text { services offered at a } \\
\text { children's hospice. }\end{array}$ & $\begin{array}{l}13 \text { suffered from } \\
\text { degenerative } \\
\text { diseases, } 12 \text { had } \\
\text { severe disabilities, } \\
\text { and } 2 \text { had cancer }\end{array}$ \\
\hline
\end{tabular}

Weidner NJ. Et al. (2011): End-of-life care for the dying child: what matters most to parents English/UK

Davies R. (2005):

Mothers' stories of loss: their need to be with their dying child and their child's body after death English/UK
To identify and define the dimensions of pediatric end-of-life (EOL) care that are important to parents who have children or infants who died either in hospital or at home under hospice care as a result of an illness, chronic condition, or birth defect.

To gain an understanding of mothers' needs based on their perspectives and to inform care and practice. To explore the loss of a child from parents' perspectives.
Malignancy; premature birth; and cardiac, neurologic, and gastrointestinal illnesses cerebral palsy, solid tumor, Maple Syrup syndrome, Hunter's disease, Hallevorden Spatz, Niemann Pick syndrome, Cogenital dystrophy
Qualitative data derived from semistructured interviews and one focus group interview with 18-20 participants Content analysis

Qualitative interviews Hermeneutic phenomenology
Parents (133 families) of children who died in the home [19] or in an a hospital (114) 29 parents (Sex: na.) from 20 families, the children of 8 of the families had received hospice care

10 mothers Child died at home, hospice or at hospital
Interviews enabled comparisons to be

made between care and support received in hospital, at home and in a children's hospice. Their stories identified their need for time, space and privacy with their dying child and their child's body after death. Also, that memories of these events continued to affect them, giving further support to new theoretical understandings of parental grief
Hospice respite care: Semi-structured epilepsy, cerebral palsy and complex special needs Home respite care: Similar to those in the hospice respite care

\section{interviews}

Constant comparison method of Strauss and Corbin (1998)
Total of 11 families receiving nursing care service in community. Hospice respite care: six families with seven children aged between 7 and 16 years

Home respite care: five families with five children aged between 3 and 15 Two families in the latter group received care both at home and in the hospice
The areas of concern identified as significant to all the families were referral to respite service, service organisation, communication, relinquishing control to respite carers and satisfaction with service needs, of receiving or in a hospice. 
Table 4 Study characteristics (Continued)

\begin{tabular}{|c|c|}
\hline $\begin{array}{l}\text { Study and } \\
\text { language/country }\end{array}$ & Aim of the study \\
\hline $\begin{array}{l}\text { Hsiao J.L. et al. (2007): } \\
\text { Parent and child } \\
\text { perspectives on } \\
\text { physician } \\
\text { communication in } \\
\text { pediatric palliative } \\
\text { care } \\
\text { English/USA }\end{array}$ & $\begin{array}{l}\text { To identify the } \\
\text { aspects of physician } \\
\text { communication that } \\
\text { children with life- } \\
\text { limiting illnesses and } \\
\text { their parents per- } \\
\text { ceived to be facilita- } \\
\text { tive or obstructive in } \\
\text { pediatric palliative } \\
\text { care. }\end{array}$ \\
\hline
\end{tabular}

Price, J. et al. (2012): Comparing the needs of families of children dying from malignant and non-malignant disease: an in-depth qualitative study English/UK experiences of compared to those
To examine the bereaved parents concerning the care provided to children who died from cancer who died from a nonmalignant condition. non-malignant condition $(n=10)$
Cancer $(n=6)$ and a
Design and Analysis Participants

20 parent (17 mothers, 1 father, 2 legal guardian) and

interviews

Children were interviewed separately from their parentswithout the parents present.

Interviews were both audio- and video taped Grounded theory child pairs of pediatric oncology and cardiology patients (mean age 14.25 years, range 9-21 years) with a poor prognosis
Qualitative in-depth interviews with bereaved parents Thematic analysis
25 parents (16 mothers and 9 the life and death of 16 children Home, hospital or hospice fathers) talked about
Hechler T. et al.

(2008):

Parents' perspective on symptoms, quality of life, characteristics of death and end-oflife decisions for children dying from cancer English/Germany
To investigate bereaved parents' perspective on five essential areas: 1) symptoms and quality of life, 2) child 's death, 3) child's death and care delivery, 4) end-of-life decisions and 5) impact of the child's death on the parents and perceived social support by the health care team characteristics of the anticipation of their

\section{Cancer \\ Leukemia, 14 brain \\ tumor, 10 \\ neuroblastoma, 9 \\ Semi-structured interviews- on distressing symptoms and quality of life of non-Hodgkin lymph- their children during oma, 3 other solid tumors e.g. soft tis- sue tumor, bone tumor the end-of-life care period, using a Ger- man version of the questionnaire devel- oped by Wolfe et al. (2000) \\ Descriptive statistics}

Parents (11 fathers and 45 mothers) of 48 children (31 boys, 17 girls) who had lost their child to cancer
Both children and

parents identified five domains of physician

communication deemed to be highly salient and influential in quality of care; relationship building, demonstration of

effort and competence, information exchange, availability, and appropriate level of child and parent involvement. Parents identified coordination of care as important communication domain

Parents of children $8 / 10$ with cancer considered care at the end of life as well resourced and responsive to their and their child's needs. In contrast, parents of children with non-malignant conditions reported under-resourced and inadequately responsive services.

$48 \%$ of the children died at home even though $88 \%$ of the parents chose 'at home' as the most appropriate locale of death in hindsight. Parents anticipated their child's death on average 9 weeks prior to the child's death. $41 \%$ of the parents provided palliative home care for their child and the majority (88\%) rated the quality of care as good or very good. $64 \%$ discussed end-oflife decisions with the health care team, 36\% did not have a discussion. Parents were clearly affected by their child's death. However, $15 \%$ of the parents were not contacted by the health care team following the child's death 
Table 4 Study characteristics (Continued)

\begin{tabular}{|c|c|}
\hline $\begin{array}{l}\text { Study and } \\
\text { language/country }\end{array}$ & Aim of the study \\
\hline $\begin{array}{l}\text { Parental decision- } \\
\text { making on utilization } \\
\text { of out-of-home res- } \\
\text { pite in children's pal- } \\
\text { liative care: Findings } \\
\text { of qualitative case } \\
\text { study research - a } \\
\text { proposed new model } \\
\text { English/Ireland }\end{array}$ & $\begin{array}{l}\text { and experiences of } \\
\text { parents of children } \\
\text { with life-limiting con- } \\
\text { ditions on out-of- } \\
\text { home respite care } \\
\text { and to present a pro- } \\
\text { posed new model of } \\
\text { care based on the } \\
\text { findings of this } \\
\text { research }\end{array}$ \\
\hline
\end{tabular}

$\begin{array}{ll}\text { Diagnosis } & \text { Design and Analysis } \\ & \text { From a larger } \\ \text { longitudinal, } & \text { qualitative case study } \\ \text { Thematic analysis } & \\ & \\ & \end{array}$

Participants

with nine families (9 vastly different needs mothers and 3 and experiences of fathers)

The children's ages ranged from 6 months to 18 years, all were under the care of a children's palliative care team Up to three interviews each respite from their own unique perspective. Crosscase comparison showed that for all parents utilizing respite care, regardless of their child's age and condition, home was the location of choice. Many interlinking factors influencing these decisions included: past experience of in-patient care, and trust and confidence in care providers. Issues were raised regarding the impact of care provision in the home on family life, siblings and the concept of home

Goldstein et al. (2013): To explore current Parents' Views of Their Child's End-ofLife Care: Sub analysis of Primary Care Involvement English/US involvement of primary care pediatricians $(P C P)^{\prime} s$ when their patients face the end of life and bereaved parents attitudes toward it.
SIDS, prematurity, Individual, in-depth, cardiac, neurological, semi-structured interoncological, $\mathrm{Gl}$ views were con"other"

ducted using a focused ethnographic technique Qualitative analysis
Vickers, J. L and Carlisle C. (2000): Choices and control: parental experiences in pediatric terminal home care English/UK
Describes the experience of caring for a dying child at home from a parent's perspective

\section{Cancer}

$\begin{array}{ll} & \text { conduct and analyze } \\ & \text { standardized, focused } \\ & \text { interviews }\end{array}$

Parents of 16 children Four categories of who died aged 1 month to 11 years were interviewed

themes was highlighted: 1) the role of individual PCP in decision making and care at end of life; 2) general attitudes about the care provided by the PCP; 3$)$ the impact of practice infrastructure on the PCP's care; and 4) bereavement involvement

"Choice and control" was the major theme that linked all the other concepts, and it appeared to be fundamental to parental coping strategies. Most parents were willing to take responsibility for the nursing care of their child, including administration of intravenous medication. The patient's home was the overwhelming choice of parents for delivery of terminal care, with most parents perceiving it as their child's choice also

Parents of 48 children Nearly all of the who had lost a child children had suffered to cancer children had suffered
from at least one von Lutzau P. et al. (2012): Children dying from cancer: Parents'
Investigated the experience of children who died of cancer,
Cancer

Semi-structured questionnaire via telephone or in 
Table 4 Study characteristics (Continued)

\section{Study and language/country}

perspectives on

symptoms, quality of

life, characteristics of

death, and end-of-life

decision

English/Germany
Aim of the study

\section{as perceived by their}

parents

as perceived by their
parents

D

$\begin{array}{ll}\text { Diagnosis } & \text { Design and Analysis } \\ & \text { person } \\ & \text { Thematic content } \\ & \text { analysis Descriptive } \\ & \text { statistics } \\ & \text { Fisher's exact test }\end{array}$

\author{
Rallison L. B and \\ Raffin- Bouchal S. \\ (2013): Living in the \\ in-between: families \\ caring for a child with \\ a progressive neuro- \\ degenerative illness \\ English/Canada
}

To explore the experience of families caring for their child at home
Steele, R.G. (2000): Trajectory of certain death at an unknown time: Children with neurodegenerative life-threatening illnesses English/Canada
To describes Neurodegenerative 1 families' perceptions life-threatening illand experiences change over time 2 the impact on the family of living with a child who has an neurodegenerative life-threatening illness (NLTI)

3 families' perceptions of the factors that influence their ability to care for their child with NLTI
Families moved through a process of navigating uncharted with their dying child. The illness trajectory of certain death at an unknown time was not a steady decline. Instead, families lived much of their lives on plateaus of relative stability where they often felt alone and isolated from healthcare professionals. Instability originated in subsequent precipitating events in the process that led to families dropping off the plateau on the way to the child's inevitable death.

Every aspect of fathers' lives was affected by their experiences, which were described in metaphoric terms as living in a dragon's shadow. Fathers dealt with life in the dragon's shadow by battling the dragon (the illness)-the core social process. Battling was a conscious, active, continuous process that required strength, willpower, and work. Battling aged between 3 and territory as they lived evitably, periods of ineceived care in home-based hospice program

$\begin{array}{ll}11 \text { interviews with } & \text { distressing symp } \\ \text { both parents and } 37 & \text { Pain and fatigue }\end{array}$ nome, life and explored the $\begin{array}{ll}\text { Cancer [5], spinal } & \text { In-depth, uns } \\ \text { muscular atrophy [2], } & \text { interviews }\end{array}$ Unstructured interviews

muscular atrophy
Progressive

Neurodegenerative Illness (PNDI)

\section{ness (NLTIs)}

Interviews together with observations of 8 families

Each family member was interviewed individually and then as a family Grounded theory
Qualitative method Audio recorded interviews phenomenology
Six families, 27 family members. A total of 6 ill children were observed

(13 interviews, including 4 couples, 4 mothers on their own, 2 siblings, 1 ill child, and 2 caregivers who were considered family)

29 family members with total of 10 sick children Children 13 years. The siblings ranged from 2 to 9 years illness

English/USA
Davies B. et al. (2004): To report findings shadow: fathers' experiences of a English/USA

\author{
serious illness that \\ they die from \\ focused on fathers of \\ focused on fathers
}

(1)


Table 4 Study characteristics (Continued)

\section{Study and language/country}

Aim of the study Diagnosis

Design and Analysis Participants

Inglin S. et al. (2011): Palliative care for children and adolescents in Switzerland: A needs analysis across three diagnostic groups English/Switzerland
To explore the perceptions and needs of families who care for a child with a life-limiting disease.
Three diagnostic groups:

(a) cancer, (b)

neurological

disorders, and (c) non-cancer/nonneurological conditions
Qualitative, explorative study Content analysis
Kars M. C. et al. (2015): The parents ability to attend to the "voice of their child" with incurable cancer during the palliative phase English/the Netherlands
To describe and offer an explanation for the parents' actions in expressing and handling of "the voice of the child".
A multicenter, qualitative research study with in-depth interviews with all parents individually Thematic analysis

ts

44 parents of 23 children (0-18 years old)

In total 57 interviews were held, of which 37 were conducted during the palliative phase and 20 soon after the child's Death. 12 parents interviewed twice and one parent three times
Results

Score

occurred within the context of fathers' experiences with fathering and fatherhood and was characterized by 3 aspects: battling with uncertainty, battling with responsibility, and battling with everyday disruption. Fathers were assisted by supportive work environments and by supportive relationships with health care providers. Unsatisfactory relationships with medical personnel compounded fathers' battling with life in the dragon's shadow child had been Irrespective of the center of care, parents of children with diagnoses other than and received palliative cancer reported a lack care or had died of support concerning within the previous 2 practical issues of care years were practical issues of care
and psychosocial aspects. Parents of children with cancer expressed difficulties related to coordination of care especially when care was provided at home. Bereaved parents emphasized their wish for bereavement support

The "voice of the child" becomes manifest in the parents' expressions of the child's needs and perceptions. Parents who actively searched to understand their child's inner perspective used direct and indirect strategies. Parents preferred indirect strategies when their child avoided talking or when they considered the conversation as threatening for the child, or for themselves. Even if the parents show an intense involvement 
Table 4 Study characteristics (Continued)

Study and Aim of the study
language/country

Diagnosis

Design and Analysis Participants

Results

in the care and

support of their child;

they can still have

difficulty

acknowledging the

child's perspective. An

inability to take into

account the child's

perspective was

largely due to the

parents' own struggle

to cope with loss.

Verberne L.M. et al.

(2017): Parental

experiences with a

paediatric palliative

care team: A

qualitative study

English/the

Netherlands
To gain insight into the parents'

experiences with a multidisciplinary

paediatric palliative

care team (PPCT),

supporting children

and families

throughout complex

palliative care

processes.
15 children had non-malignant disease and 9 children had a malignant disease
Interpretative qualitative study Inductive thematic analysis
42 parents ( 24 mothers, 18 fathers) of 9 children (0-> 16) In total, 47 interviews of which 11 parents were interviewed after the child's death

In advance, parents had limited

expectations of the paediatric palliative care team. Some had difficulty accepting the need for palliative care for their child. Once parents experienced what the team achieved for their child and family, they valued the team's involvement. Valuable elements were as follows: [1] process-related aspects such as continuity, coordination of care, and providing one reliable point of contact [2]; practical support; and [3] the team members' sensitive and reliable attitude.

Eskola K, Bergstraesser To understand E, Zimmermann K. Cignacco E. (2017): Maintaining family life balance while facing a child's imminent death-A mixed methods study English/Switzerland (EOL) care parents' experiences and needs during a child's end-of-life at home and to identify systemic factors that influence its provision. To provide a comprehensive understanding of parental experiences and needs during their child's EOL care at home and to determine which system factors influenced provision of EOL home care in Switzerland.
Cardiac, neurological Concurrent or oncological embedded mixed condition methods design Quantitative data were extracted from: [1] a retrospective chart review and [2] a parental questionnaire survey and qualitative data from semi-structured parental interviews Thematic analysis and merging qualitative and quantitative data
10 interviews (7 mothers, 1 father and 2 couples) Children 0-18

Parents created an intimate lifeworld and a sense of normality for the child at home. They constantly balanced the family's lifeworld with the requirements and challenges posed by the outside world. This work exhausted parents. Parental 'readiness' and social support drove EOL care for children at home. Parents needed practical help with housekeeping and had negative experiences when dealing with insurance. In only $34.8 \%$ of cases was a child's EOL home care supported by paediatric palliative care team

(


Table 4 Study characteristics (Continued)

\section{Study and language/country}

Hansson $\mathrm{H}$, Hallström

I,K. (2017): A

possibility for

strengthening family

life and health: Family

members' lived

experience when a

sick child receives

home care in Sweden

English/Sweden

\section{Aim of the study}

members' lived experience when a sick child received home care from county-based primary healthcare services.

Diagnosis
disease, congenital
hiatal hernia, heart
disease and Lyme
disease

Design and Analysis Participants

Results

CASP

qualitative design

(6 months to 14

lived experience was

Interviews

A hermeneutic years), 10 siblings (3phenomenological 16 years) and 23 approach parents

dhree

"Strengthening family life" relates to how

home care induced freedom and luxury in a strained period of life and supported the families' everyday life. Usual social activities and relations were maintained as time and energy was saved when receiving home care. "Promoting health" relates to how the family members' burden of illness decreased as the child's signs of illness alleviated and the well-being of the whole family increased when the child received care in the home. This provided a peaceful respite for family members' psychosocial recovery. The third theme, "Creating alliances," relates to the importance of creating trustful alliances for communicating participation in care. If trustful alliances were not created, parents felt an overwhelming responsibility and family members became anxious

Mariyana R,

Allenidekania A, Nurhaeni N. (2018):

Parents' Voice in Managing the Pain of Children with Cancer during Palliative Care English/Indonesia
To know how the experiences of mothers managing their children's pain during palliative care following cancer diagnosis cancer

semi-structured interviews using snowball sampling descriptive phenomenology
8 participants, comprised of 7 mothers and 1 father
Identifications of 8 themes: the dimensions of pain experienced by children undergoing palliative care; mothers' physical and psychological responses; mothers' emotional responses; barriers encountered by mothers when taking care of their child at home; mothers' interventions to reduce their child's pain; mothers' efforts to distract their child from pain; giving encouragement when the child is in pain; and mothers' efforts and prayers to make

in

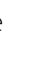


Table 4 Study characteristics (Continued)

\begin{tabular}{ll}
\hline $\begin{array}{l}\text { Study and } \\
\text { language/country }\end{array}$ & Aim of the study \\
\hline & \\
Imperal-Perez F. & $\begin{array}{l}\text { To explore and } \\
\text { describe the }\end{array}$ \\
Heilemann M.V. & perceptions and lived \\
(2019): Having to Be & experiences of \\
the One: Mothers & mothers of infants \\
Providing Home Care & after palliative or \\
to Infants With & corrective surgery for \\
Complex Cardiac & complex CHD at birth \\
Needs & who were discharged \\
English/USA & to home and \\
& subsequently \\
& readmitted.
\end{tabular}

Verberne L.M. et al. To provide a generic (2017): Aims and tasks and

in parental caregiving comprehensive for children receiving overview of parental palliative care at home: a qualitative study English/The Netherlands

Verberne L.M. et al. (2019): Parental experiences and coping strategies when caring for a child receiving paediatric palliative care: a qualitative study English/The Netherlands caregiving, based on the lived experience of parents caring for a child with a LLD.

\author{
Diagnosis \\ heart disease theory \\ Malignant (MD) and Single or repeated \\ non-malignant diag- interviews \\ noses (NMD)

(n)

Design and Analysis Participants

Results

complex congenital Interviews grounded 10 mothers

To provide insight into the most prominent experiences of parents caring for a child with a

malignant or nonmalignant LLD/LTD at home and to identify the main coping strategies they adopt to allow themselves to continue with their daily lives. death.

47 interviews telephone with 42 (0-18)

24 mothers and 18 fathers quality managing
Malignant (MD) and Single or repeated non-malignant diag- interviews noses (NMD)

An interpretive qualitative study using an inductive thematic analysis
Same sample as Verberne L.M. et al. 2017. See above

their child comfort.

1 category, "having to $8 / 10$ be the one," which had 3 properties: having no choice but to provide complex care at home, handling unexpected roles, and grappling with the possibility of

Parents strived to be a 'good parent', parents of 24 children parents caring for a

child with a life-

limiting disease strived for three aims: controlled symptoms and controlled disease, a life worth living for their ill child and family balance. These aims resulted in four tasks that parents performed: providing basic and complex care, organising good care and treatment, making sound decisions while risks and organising a good family life.

Prominent reported parental experiences were daily anxiety of child loss, confrontation with loss and related grief, ambiguity towards uncertainty, preservation of a meaningful relationship with their child, tension regarding end-of-life decisions and engagement with professionals. Four closely related coping strategies were identified: suppressing emotions by keeping the loss of their child at bay, seeking support, taking control to arrange optimal childcare and adapting to and accepting the ongoing change(s). 
presence of the parents, was crucial for some of the children [26].

\section{Siblings' experiences}

Only three papers highlighted the experiences of siblings $[21,27,32]$. Steele (2000) reported that siblings felt sadness when losing a brother or sister and playmate, but also anger or distress as parents gave more attention to the dying child. One of the articles reported interviewing two siblings and stated that the sibling planned a career as a health care professional based on their experience with the sick sibling [27]. Receiving palliative care at home made it possible for siblings to maintain contact with friends and attend school, and contributed to maintaining a normal everyday life and keeping the family together [21].

\section{Challenges and unmet needs at home Challenges}

The families experienced a range of challenges and difficulties due to the coordination of care [33], or lack of support and adequately skilled staff with appropriate experience [34]. Children could even be readmitted to hospital due to an absence of skilled nurses to provide home care [35]. Another obstacle was that organising home care took too long to establish 'Community nursing we found incredibly frustrating...they had actually appointed so many people; 7 carers. Amelia couldn't come home until these carers had been interviewed vetted and everything, work their 3 months' notice in their present jobs, then had to be trained but by this stage, Amelia died before they got this all done so she never got home'. (Informant in Price et al., 2012) [34]..

Even though health care providers played a significant role in parents' experience of end-of-life care [36], some parents highlighted the challenge of having health care providers present all the time due to the importance of spending time with their child without interference from the health care team [37].

Some parents experienced lack of trust in primary caregivers and reported that caregivers were absent at crucial times [36]. Others spoke positively about the care, and were satisfied with the primary caregiver's efforts. Also, health care providers' involvement in bereavement was important for parents, and some parents even wanted the care providers to attend the child's funeral [36]. Families' living conditions due to the family economy was challenging for some parents because of the parents' (mostly the mother's) withdrawal from the labour market, resulting in lower income [27, 38], and the cost of medication and equipment was a significant burden [27]. Parents also reported that they would have appreciated more attention from health care providers to siblings at the time of the loss. More interest in siblings' coping and awareness of loss may help these children later in life [36].

\section{Needs}

Parents need health care professionals to communicate relevant information [33], listen to the parents and give information in a straightforward way. Such communication with health care professionals must be reciprocal and honest $[26,33,37]$. Good communication is exemplified as the person having a sensitive and reliable attitude [39]. Families experienced an incredible workload due to the child's illness [32, 38, 40], which included managing the physical, cognitive and emotional work generated by the situation, while also attending to everyday pursuits [32]. The demanding care situation limited flexibility in daily life and made it challenging to meet the needs and interests of all family members [40, 41]. Parents sometimes had a bad conscience in relation to siblings who were given little attention due to tasks and the urgent needs of the sick child [40]. Parents of children with non-malignant conditions had an even less sensitive and flexible set of services compared with the families of children with cancer [34]. Less developed and less accessible and flexible infrastructure for these families created additional burdens, and instead of focusing on their child, the families were forced to fight for resources [34]. Along with the illness trajectory and change in the child's condition, the families had different needs. Time, space and privacy to be with their dying child were important, and in end-of-life-care, parents needed both time and space to be with their dying child, but also time to be with the child's body after death [42].

\section{Importance of support and respite care}

Respite was emphasised as important for parents' coping [43] and was an important part of children's palliative care. Important factors included the range of care, services and distance to respite care, as well as staff turnover and trust in health care personnel [44]. The parents reported that a pediatric care team provided practical support and continuity throughout the palliative trajectory and coordination of care [34]. Some parents preferred home-based respite, as it was difficult to leave the child in hospital and hand over their care to others, as the parents were the experts in caring for their child [40, 44]. Respite had positive effects like improved sleep, a feeling of freedom and liberation from responsibility, and the parents' time to live as a couple [38]. Benefits from respite care also included the child having fun and enjoying the stay when respite was provided outside the family home [38]. 


\section{Discussion}

Home is the preferred place for a majority of the families in these studies. A paramount issue in the review was the need for support, information and respite care when caring for a child at home. The quality of collaboration between health care professionals and the families has a significant impact on the family's experience when caring for the child at home. Although approximately 300 children in palliative care are included in this systematic review, the voices of the children themselves are seldom heard. Furthermore, the experiences of siblings are seldom addressed. The child's perspective narrated by the child itself is almost non-existing in this research, and the narratives are mainly produced by the child's parents, most frequently the mother.

\section{The need for support and respite care when caring for a child at home}

All family members, including the sick child, parents and siblings, need support, care and supervision in order to be able to care for the seriously ill child. Although respite was highlighted as an integral part of children's palliative care at home [44], and an important factor for coping and managing daily life in a demanding situation, access to resources was demanding [38]. The present review indicates that support from competent palliative home-care teams was an important factor to promote well-being and to increase the families' quality of life at home $[21,30]$. A previous study stated that poorly developed health care services for these families and bureaucratising processes might be unnecessary obstacles for the families, resulting in the child dying in hospital rather than at home [34]. A systematic review underpin the complexity of families experiences of palliative care at home [15] and place of care depends on facilities offered, distance of service from home, home care availability and children's underlying conditions [15]. Even though some countries have a well-established program for children's palliative care $[9,12]$ the present review point at unmet needs and the potential for improvement, even though most of the studies are from countries with well-developed palliative care services for children (see Table 4). A study by Dussel et al. (2013), looked at determinants and effects of planning a child's location of death and found that actual place of death may be less important than has been argued. However, planning was a key issue and children of parents who planned location of death were more likely to dye at home [45]. Further in this study, comprehensive communication with the physician was found to be facilitator for location of death. This is in line with a study in our review that found that the alliance between the family, home care and hospital care was a condition for the success of home-based care [21], which support the importance of communication. Other communicative dimensions expressed was information, both between the child, family and friends, and between the families and health care providers [33, 37]. Parents underlined the importance of being listened to and being prepared for bad news or the consequences of treatment, and appreciated being informed in a straightforward way. Parents also appreciated that the health care professionals spent time explaining and providing more complete information, and also let the child know about his or her condition and prognosis. Respecting the child and the families in this way could possibly strengthen the communication between family members, as well as ensure reciprocal and honest communication with health care professionals [26, 33, 37]. Communication between the parents, the provision of available information about the child's condition, the parents' relationship with the health care professionals, and even different ways of grieving, created difficult situations for the families [46]. Another aspect of importance to the parents was that health care providers communicated hope [24]. Breaking bad news in an insensitive manner, withholding information, or having a disrespectful or arrogant attitude potentially led to ineffective communication about difficult decisions [26]. Meta-summary findings suggest that changes are needed in practice, combined with policy, to ensure the health and well-being of the family, and for caregivers to maintain this, families should be offered support during both caregiving and bereavement [47, 48]. The studies included in this review show that the organisation of and access to palliative care varies (see Table 4). An overview of palliative care in Europe (EAPC Atlas of Palliative Care in Europe), highlights the inequality between countries and sub-regions regarding policy, education, use of medication, service provision and professional activities [49]. This variation in the field suggests different opportunities for families to make real choices concerning the place of palliative care for their child and place for a peaceful death.

\section{Children's experiences and needs}

Despite the fact that the children are the patients and the main subjects of the studies, their mothers (194) are the most frequently interviewed. The families in the studies represent approximately 300 children with palliative care needs, but few of the children themselves are interviewed. Children reported that they wanted to stay at home [21] so that school mates could stop by for a visit on their way home from school, and grandparents could come to dinner, give their support and spend time with their grandchildren. Some children expressed that travelling to the hospital required both time and energy [21]. If health care providers could come to the children's home, the child could use their precious time and energy on meaningful 
activities instead of on travelling back and forth to hospital for minor procedures. Children have independent needs, for example talking with their physician without the present of their parents [26]. There are differences in how parents want health care professionals to talk to their children. Some wanted the health care professionals to give them information first, and then decide what information was suitable for their child [26]. Parents' opinions and experiences are important, as they know their child best, but parents might have difficulties acknowledging the child's perspective because of their own struggle with loss [28]. Children's participation in research is compromised since children are generally considered a vulnerable population because of their intellectual and emotional capacity [50]. There may be ethical and professional considerations for not interviewing children in palliative care, but also good reasons for talking to children, because they may disagree with their parents [26]. It is important to enhance children's opportunities and right to be heard [51], and include researchers with specific skills and training related to children and sensitive topics, who choose research methods appropriate for children's participation. The view of the child as competent has become more prominent [52], and children are not only vulnerable, but also social actors who may hold a more central role in decisionmaking in terms of participation in research [50]. Through communication with children, we can strengthen their participation in democracy, recognising them as members of society, and include them as decision-makers in matters that concern their own life [53]. Children may also find participation in studies to be useful [54]. Castor et al. (2018) included children in family interviews, letting them take an active part according to their age, stage of illness and cognitive development [21]. The interviews were performed with a family member present, and the conversation was started with open-ended questions using pictures taken by the family. Other methods for data collection might be to include drawings or play as an opener for conversation [55]. The importance of being sensitive to the child and treating the child as an individual is emphasised. Researchers must also be sensitive to ethical issues and ask questions in a language suitable for the child's age, development and cognitive ability. Furthermore, researchers must take into account the children's emotional and cognitive development, their experience of illness and death, the families' coping and the possibility of receiving information, as such factors are important to the child's ability to understand and adjust to severe illness and death [56].

\section{Difficult feelings experienced by siblings}

Siblings struggled with difficult feelings and worries about their brother or sister's suffering [32]. Siblings also suffered from too little attention from their parents [32], and parents realised that siblings came in 'second place'
[40]. Siblings often got little or no information during the last $24 \mathrm{~h}$ before the loss of their sister or brother, and $84 \%$ of the siblings experienced that nobody talked to them about what to expect when their brother/sister was dying [57]. Siblings were often forgotten or overlooked. Emotional reactions were anxiety concerning their brother's/sister's pain, powerlessness, helplessness, fear of death, jealousy towards their brother/sister, the uncertainty of waiting for death, and distress at seeing their brother/sister suffering [57]. Siblings who are not adequately safeguarded may experience post-traumatic stress syndrome, poor quality of life and a sense of loneliness later in life [58]. Eilertsen et al. (2013) also reported that bereaved siblings had a greater probability of reporting self-assessed anxiety when their need for social support was not satisfied prior to and following their sibling's death. Information provided to families by nurses and health care professionals about the impact of social support may contribute to lessening the siblings' risk of anxiety [59]. To promote siblings' emotional health, interventions should address the complexity of siblings' feelings [60]. Siblings should also be given appropriate information about the illness trajectory, and what to expect when the death of a sister or brother is approaching. Information communicated in a sensitive way may reduce anxiety, as higher levels of anxiety may result from having no one to talk to about what to expect [57]. These findings are relevant regardless of the sick brother or sister's place of care.

\section{Strengths and limitations}

A methodological strength of the study is that six researchers have read and discussed the papers and at least two researchers have read each paper. We have included English language databases only, and excluded Nordic language databases. The studies were mainly qualitative studies with a limited number of participants and not designed to be representative at the population level. A quality assessment showed that ethical issues concerning the relationship between researchers and participants were weak in the majority of the papers.

Some papers had unclear explanations of ethical issues, and the recruitment of parents in such a dramatic life situation should have been accounted for.

The reason for there being more available research from this part of the world may be that it has longer traditions of hospice and palliative care. Since some studies were not specific enough concerning the place of care, some relevant papers may have been omitted.

\section{Implication for future research}

The results of this systematic review underpin the lack of research on the sick children and their siblings' perspectives on palliative care at home. Children in 
palliative care should be given an opportunity to express and communicate their experiences, feelings and needs themselves, and not only through their parents. Their experience is important for optimising the quality of care at the end of life, and identifying the needs of these vulnerable children is crucial. There is a gap in the knowledge about children's needs that further research should address. Furthermore, few countries are represented in the literature on families' experiences with palliative care for children at home, with most studies stemming from North America, Canada and the United Kingdom.

\section{Conclusion}

Based on the experiences of the families in this review, we will highlight five areas that deserve more attention. First of all, the families need organised, individualised support from a skilled pediatric palliative care team. Secondly, respite care is necessary in order to manage a demanding home-care situation. Further, parents need help with and support for siblings both because the siblings need attention, but also to reduce the parents' bad conscience in relation to giving them less attention. Privacy to be a family is a further need, and, finally, many families need financial support.

\section{Abbreviations}

LL: Life-limiting; LT: Life-threatening; QoL: Quality of Life; PPC: Pediatric

Palliative Care

\section{Acknowledgements}

Thank you to Academic Librarian Malene Wøhlk Gundersen for discussions and help with the initial searches for papers in this systematic review.

\section{Ethical approval and consent to participation}

This systematic review is based on published results from research performed by other researchers and does not directly involve human participants, human material, or human data. We therefore consider this issue as Not applicable.

\section{Consent to publication}

This issue is not applicable because this systematic review is based on published results from research performed by other researchers and does not directly involve human participants, human material, or human data.

\section{Declarations}

The authors declare that they have no financial and non-financial competing interests. The corresponding author confirms that the submission guidelines available on the journal website have been read.

\section{Authors' contributions}

AW conceived the study, developed and performed the searches, organised the work, screened the citations and full text articles, abstracted data, critically considered quality, analysed the data, interpreted the results, generated tables and figures and wrote the manuscript. IHR developed and performed the searches, screened the citations and full text articles, abstracted data, critically considered quality, analysed the data, wrote the manuscript, critically revised the manuscript for important intellectual content and approved the final manuscript as submitted. LGK developed searches, screened the citations and full text articles, abstracted data, critically considered quality, analysed the data, wrote the manuscript, critically revised the manuscript for important intellectual content and approved the final manuscript as submitted. BL developed searches, screened the citations and full text articles, interpreted the results, generated the flow chart, critically revised the manuscript for important intellectual content and approved the final manuscript as submitted. SH developed searches, screened the citations and full text articles, critically revised the manuscript for important intellectual content and approved the final manuscript as submitted. CK developed searches, screened the citations and full text articles, critically revised the manuscript for important intellectual content and approved the final manuscript as submitted. All authors consent to publication.

\section{Funding}

OsloMet - Oslo Metropolitan University funded this study by providing time for the researchers and the Academic Librarian to conduct the study. Additionally the institution provided translation costs and open access publication.

\section{Availability of data and materials}

All data generated or analysed during this study are included in this published article as search strategy in Table 2 (attached), and; the 23 articles on which this review is based are attached as Table 4.

\section{Competing interests}

The authors declare that they have no competing interests.

\section{Author details}

${ }^{1}$ Oslo Metropolitan University (OsloMet), P.O. Box 4 St. Olavs plass, NO-0130 Oslo, Norway. ${ }^{2}$ Oslo University Hospital HF, P.O. Box 4950 Nydalen, NO-0424 Oslo, Norway.

Received: 11 May 2020 Accepted: 15 October 2020

Published online: 24 October 2020

\section{References}

1. Connor SR, Downing J, Marston J. Estimating the global need for palliative Care for Children: a cross-sectional analysis. J Pain Symptom Manag. 2017; 53(2):171-7. https://doi.org/10.1016/j.jpainsymman.2016.08.020.

2. Fraser LK, Miller M, Hain R, Norman P, Aldridge J, McKinney PA, et al. Rising national prevalence of life-limiting conditions in children in England. Pediatrics. 2012;129(4):e923-9. https://doi.org/10.1542/peds.2011-2846.

3. Meghani SH. A concept analysis of palliative care in the United States. J Adv Nurs. 2004;46(2):152-61. https://doi.org/10.1111/j.1365-2648.2003.02975.x.

4. Definition of Palliative Care. Worlds Health Organization. 1998. Tilgjengelig fra: http://www.who.int/cancer/palliative/definition/en/.

5. Heath JA, Clarke NE, Donath SM, MCCarthy M, Anderson VA, Wolfe J. Symptoms and suffering at the end of life in children with cancer: An Australian perspective. Med J Australia. 2010;192(2):71-5. https://doi.org/10. 5694/j.1326-5377.2010.tb03420.x

6. Bogetz JF, Ullrich CK, Berry JG. Pediatric hospital care for children with lifethreatening illness and the role of palliative care. Pediatr Clin. 2014;61(4): 719-33. https://doi.org/10.1016/j.pcl.2014.05.002.

7. Pousset G, Bilsen J, Cohen J, Addington-Hall J, Miccinesi G, OnwuteakaPhilipsen B, et al. Deaths of children occurring at home in six European countries. Child Care Health Dev. 2010;36(3):375-84. https://doi.org/10.1111/ j.1365-2214.2009.01028.x.

8. Beardsmore S, Fitzmaurice N. Palliative care in paediatric oncology. [Oxford]; 2002. p. 1900-7.

9. Kassam A, Skiadaresis J, Alexander S, Wolfe J. Parent and clinician preferences for location of end-of-life care: home, hospital or freestanding hospice? Pediatr Blood Cancer. 2014;61(5):859-64. https://doi.org/10.1002/ pbc.24872.

10. Bradford N, Armfield NR, Young J, Smith AC. The case for home based telehealth in pediatric palliative care: a systematic review. BMC Palliat Care 2013;12:4. https://doi.org/10.1186/1472-684X-12-4.

11. Himelstein BP, Hilden JM, Boldt AM, Weissman D. Pediatric palliative care. $N$ Engl J Med. 2004;350(17):1752-62. https://doi.org/10.1056/NEJMra030334.

12. Siden $H$, Miller M, Straatman $L$, Omesi L, Tucker T, Collins JJ. A report on location of death in paediatric palliative care between home, hospice and hospital. Palliat Med. 2008;22(7):831-4. https://doi.org/10.1177/ 0269216308096527.

13. Heckford $E$, Beringer AJ. Advance care planning: challenges and approaches for pediatricians. J Palliat Med. 2014;17(9):1049-53. https://doi.org/10.1089/ jpm.2013.0374. 
14. Afari N, Buchwald D. Chronic fatigue syndrome: a review. Am J Psychiatry. 2003;160(2):221-36. https://doi.org/10.1176/appi.ajp.160.2.221.

15. Bluebond-Langner $M$, Beecham E, Candy B, Langner R, Jones L. Preferred place of death for children and young people with life-limiting and lifethreatening conditions: a systematic review of the literature and recommendations for future inquiry and policy. Palliat Med. 2013;27(8):70513. https://doi.org/10.1177/0269216313483186.

16. Virdun C, Brown N, Phillips J, Luckett T, Agar M, Green A, et al. Elements of optimal paediatric palliative care for children and young people: an integrative review using a systematic approach. Collegian. 2015;22(4):42131. https://doi.org/10.1016/j.colegn.2014.07.001.

17. European Association for Palliative Care. IMPaCCT: standards for paediatric palliative care in Europe. Eur Jour Pall Car. 2007;14(3):109-14.

18. Dixon-Woods M, Agarwal S, Jones D, Young B, Sutton A. Synthesising qualitative and quantitative evidence: a review of possible methods. J Health Serv Res Policy. 2005;10(1):45-53. https://doi.org/10.1177/ 135581960501000110.

19. Critical Appraisal Skills Programme. CASP qualitative ChecklistUK. (n.d.) https://casp-uk.net/casp-tools-checklists/. Accessed 01 June 2017.

20. Eskola K, Bergstraesser E, Zimmermann K, Cignacco E. Maintaining family life balance while facing a child's imminent death-A mixed methods study. J Adv Nurs. 2017;73(10):2462-72. https://doi.org/10.1111/jan.13304.

21. Castor $\mathrm{C}$, Landgren $\mathrm{K}$, Hansson $\mathrm{H}$, Kristensson HI. A possibility for strengthening family life and health: family members' lived experience when a sick child receives home care in Sweden. Health Soc Care Community. 2018;26(2):224-31. https://doi.org/10.1111/hsc.12512.

22. Hechler T, Blankenburg M, Friedrichsdorf S, Garske D, Hubner B, Menke A, et al. Parents'perspective on symptoms, quality of life, characteristics of death and end-of-life decisions for children dying from cancer. Klin Padiatr. 2008;220:166-74. https://doi.org/10.1055/s-2008-1065347.

23. Vickers $\lrcorner$, Carlisle $C$. Choices and control: parental experiences in pediatric terminal home care. J Pediatr Oncol Nurs. 2000;17(1):12-21. https://doi.org/ 10.1177/104345420001700103.

24. von Lutzau P, Otto M, Hechler T, Metzing S, Wolfe J, Zernikow B. Children dying from cancer: Parents' perspectives on symptoms, quality of life, characteristics of death, and end-of-life decisions. J Palliat Care. 2012;28(4): 274-81. https://doi.org/10.1177/082585971202800406.

25. Davies B, Gudmundsdottir M, Worden B, Orloff S, Sumner L, Brenner P. "living in the dragon's shadow" fathers' experiences of a child's life-limiting illness. Death Stud. 2004;28(2):111-35. https://doi.org/10.1080/ 07481180490254501.

26. Hsiao JL, Evan EE, Zeltzer LK. Parent and child perspectives on physician communication in pediatric palliative care. Palliat Support Care. 2007;5(4): 355-65. https://doi.org/10.1017/s1478951507000557.

27. Rallison LB, Raffin-Bouchal S. Living in the in-between: families caring for a child with a progressive neurodegenerative illness. Qual Health Res. 2013; 23(2):194-206. https://doi.org/10.1177/1049732312467232.

28. Kars MC, Grypdonck MH, de Bock LC, van Delden JJ. The parents' ability to attend to the "voice of their child" with incurable cancer during the palliative phase. Health Psychol. 2015;34(4):446-52. https://doi.org/10.1037/ hea0000166.

29. Nelson H, Mott S, Kleinman ME, Goldstein RD. Parents' experiences of pediatric palliative transports: a qualitative case series. J Pain Symptom Manag. 2015 50(3):375-80. https://doi.org/10.1016/j.jpainsymman.2015.04.004.

30. Vollenbroich R, Borasio GD, Duroux A, Grasser M, Brandstatter M, Fuhrer M. Listening to parents: the role of symptom perception in pediatric palliative home care. Palliat Support Care. 2016;14(1):13-9. https:/doi.org/10.1017/S1478951515000462.

31. Verberne LM, Kars MC, Schouten-van Meeteren AYN, van den Bergh EMM, Bosman DK, Colenbrander DA, et al. Parental experiences and coping strategies when caring for a child receiving paediatric palliative care: a qualitative study. Eur J Pediatr. 2019;178(7):1075-85. https://doi.org/10.1007/ s00431-019-03393-w.

32. Steele RG. Trajectory of certain death at an unknown time: children with neurodegenerative life-threatening illnesses. Can J Nurs Res. 2000;32(3):4967 doi:https://cjnr.archive.mcgill.ca/article/viewFile/1590/1590.

33. Inglin S, Hornung R, Bergstraesser E. Palliative care for children and adolescents in Switzerland: a needs analysis across three diagnostic groups. Eur J Pediatr. 2011;170. https://doi.org/10.1007/s00431-011-1398-5.

34. Price J, Jordan J, Prior L, Parkes J. Comparing the needs of families of children dying from malignant and non-malignant disease: an in-depth qualitative study. BMJ Support Palliat Care. 2012;2(2):127. https://doi.org/10. 1136/bmjspcare-2011-000104.

35. Mariyana R, Allenidekania A, Nurhaeni N. Parents' voice in managing the pain of children with Cancer during palliative care. Indian J Palliat Care. 2018;24(2):156-61.

36. Goldstein R, Rimer KP. Parents' views of their child's end-of-life care: subanalysis of primary care involvement. J Palliat Med. 2013;16(2):198-202. https://doi.org/10.1089/jpm.2012.0269.

37. Weidner NJ, Cameron M, Lee RC, McBride J, Mathias EJ, Byczkowski TL. Endof-life care for the dying child: what matters most to parents. J Palliat Care. 2011:27(4):279-86. https://doi.org/10.1177/082585971102700404.

38. Champagne M, Mongeau S. Effects of respite care services in a children's hospice: the parents' point of view. J Palliat Care. 2012;28(4):245-51.

39. Verberne LM, Schouten-van Meeteren AY, Bosman DK, Colenbrander DA, Jagt CT, Grootenhuis MA, et al. Parental experiences with a paediatric palliative care team: A qualitative study. Palliat Med. 2017;31(10):956-63. https://doi.org/10.1177/0269216317692682.

40. Verberne LM, Kars MC, Schouten-van Meeteren AY, Bosman DK, Colenbrander DA, Grootenhuis MA, et al. Aims and tasks in parental caregiving for children receiving palliative care at home: a qualitative study. Eur J Pediatr. 2017:176(3):343-54. https://doi.org/10.1007/s00431-016-2842-3.

41. Imperial-Perez F, Heilemann MV. Having to Be the One: Mothers Providing Home Care to Infants With Complex Cardiac Needs. Am J Crit Care. 2019; 28(5):354-60. https://doi.org/10.4037/ajcc2019887.

42. Davies R. Mothers' stories of loss: their need to be with their dying child and their child's body after death. J Child Health Care. 2005;9(4):288-300. https://doi.org/10.1177/1367493505056482.

43. Eaton N. I don't know how we coped before': a study of respite care for children in the home and hospice. J Clin Nurs. 2008;17(23):3196-204. https://doi.org/10.1111/j.1365-2702.2008.02630.x.

44. Ling J, Payne S, Connaire K, McCarron M. Parental decision-making on utilisation of out-of-home respite in children's palliative care: findings of qualitative case study research - a proposed new model. Child Care Health Dev. 2016:42(1):51-9. https://doi.org/10.1111/cch.12300.

45. Dussel V, Kreicbergs U, Hilden JM, Watterson J, Moore C, Turner BG, et al. Looking beyond where children die: determinants and effects of planning a Child's location of death. J Pain Symptom Manag. 2009;37(1):33-43. https:// doi.org/10.1016/j.jpainsymman.2007.12.017.

46. Steele RG. Experiences of families in which a child has a prolonged terminal illness: modifying factors. Int J Palliat Nurs. 2002;8(9):418-34. https://doi.org/ 10.12968/ijpn.2002.8.9.10687

47. Bally JMG, Smith NR, Holtslander L, Duncan V, Hodgson-Viden H, Mpofu C, et al. A Metasynthesis: uncovering what is known about the experiences of families with children who have life-limiting and life-threatening illnesses. J Pediatr Nurs. 2018;38:88-98. https://doi.org/10.1016/j.pedn.2017.11.004.

48. Holtslander L, Baxter S, Mills K, Bocking S, Dadgostari T, Duggleby W, et al. Honoring the voices of bereaved caregivers: a Metasummary of qualitative research. BMC Palliative Care. 2017;16(1):48. https://doi.org/10.1186/s12904-017-0231-y.

49. Arias-Casais N, Garralda E, Rhee JY, Lima LD, Pons JJ, Clark D, et al. EAPC Atlas of Palliative Care in Europe 2019. 2019.

50. Powell MA, Smith AB. Children's participation rights in research. Childhood. 2009;16(1):124-42. https://doi.org/10.1177/0907568208101694.

51. UN. Convention on the Rights of the Child. United Nations. Treaty Ser. 1989; 1577(3).

52. Skivenes M, Strandbu A. A Child Perspective and Children's Participation. Child Youth Environ. 2006;16(2):10-27 doi:https://www.jstor.org/stable/10. 7721/chilyoutenvi.16.2.0010.

53. Percy-Smith B, Thomas N. A handbook of children and young people's participation : perspectives from theory and practice. London: Routledge; 2010.

54. Dyregrov K, Dyregrov A, Raundalen M. Refugee families' experience of research participation. J Trauma Stress. 2000;13(3):413-26. https://doi.org/10. 1023/A:1007777006605.

55. Kirk S. Methodological and ethical issues in conducting qualitative research with children and young people: A literature review. Int J Nurs Stud. 2007. 44(7):1250-60. https://doi.org/10.1016/j.jinurstu.2006.08.015.

56. Reinfjell TVA, Diseth T. Barns forståelse og tilpasning til alvorlig sykdom og død. , 4, 11-16. Omsorg. 2014;4:11-6.

57. Lövgren $M$, Jalmsell L, Eilegård Wallin A, Steineck G, Kreicbergs U. Siblings' experiences of their brother's or sister's cancer death: a nationwide followup 2-9 years later. Psycho-Oncology. 2016;25(4):435-40. https://doi.org/10. 1002/pon.3941. 
58. Jones BL, Contro N, Koch KD. The Duty of the Physician to Care for the Family in Pediatric Palliative Care: Context, Communication, and Caring. Pediatrics. 2014;133(Supplement 1):S8-S15. https://doi.org/10.1542/peds. 2013-3608C.

59. Eilertsen ME, Eilegard A, Steineck G, Nyberg T, Kreicbergs U. Impact of social support on bereaved siblings' anxiety: a nationwide follow-up. J Pediatr Oncol Nurs. 2013;30(6):301-10. https://doi.org/10.1177/1043454213513838.

60. Haukeland YB, Fjermestad KW, Mossige S, Vatne TM. Emotional experiences among siblings of children with rare disorders. J Pediatr Psychol. 2015;40(7): 712-20. https://doi.org/10.1093/jpepsy/jsv022.

\section{Publisher's Note}

Springer Nature remains neutral with regard to jurisdictional claims in published maps and institutional affiliations.

Ready to submit your research? Choose BMC and benefit from:

- fast, convenient online submission

- thorough peer review by experienced researchers in your field

- rapid publication on acceptance

- support for research data, including large and complex data types

- gold Open Access which fosters wider collaboration and increased citations

- maximum visibility for your research: over $100 \mathrm{M}$ website views per year

At $\mathrm{BMC}$, research is always in progress.

Learn more biomedcentral.com/submissions 